\title{
Biological effects of BMP7 on small-cell lung cancer cells and its bone metastasis
}

\author{
WEIWEI SHEN ${ }^{*}$, HAILIN PANG* ${ }^{*}$ BO XIN, LIAN DUAN, LILI LIU and HELONG ZHANG \\ Department of Oncology, Tangdu Hospital, The Fourth Military Medical University, Xi'an, Shaanxi 710038, P.R. China
}

Received January 30, 2018; Accepted June 11, 2018

DOI: 10.3892/ijo.2018.4469

\begin{abstract}
Small-cell lung cancer (SCLC) is typically fatal if untreated. It is characterized by early and widespread metastases, and has the ability to rapidly develop resistance to chemotherapy. Bone morphogenetic protein 7 (BMP7), a member of the BMP family of signaling molecules, has been implicated in various types of cancer, particularly prostate cancer and breast cancer. However, there is little knowledge of the function of BMP7 in SCLC. The aim of the present study was to investigate the biological function of recombinant human (rh)BMP7 on SCLC cells and the underlying molecular basis for this regulatory mechanism. The effect of rhBMP7 on SCLC cell lines and associated signaling pathways was investigated. Results suggested that rhBMP7 significantly inhibited the proliferation, motility and invasion of SBC-3 and SBC-5 cells. However, rhBMP7 exhibited no effect on the apoptosis of SBC-5 cells, but promoted apoptosis of SBC-3 cells. Furthermore, cell cycle analysis revealed that rhBMP7 was able to increase the proportion of cells in $\mathrm{G}_{1}$ phase and decrease the $S$ phase proportion. Total and membrane BMP receptor (BMPR)IA and BMPRIB were highly expressed in SBC-5 cells, whereas cytoplasmic BMPRIA and BMPRIB expression was higher in SBC-3 cells. However, activin A receptor type I expression was higher in SBC-3 cells in total and cytoplasmic proteins. Furthermore, following stimulation with rhBMP7, Smad2, Smad4 and p21 were downregulated. We hypothesized that rhBMP7 inhibited the progressiveness of SCLC cells by inducing $G_{1}$ phase arrest and inhibiting $S$ phase entry. The results of the present study indicated that BMP7 serves a key function in regulating the progression of SCLC.
\end{abstract}

Correspondence to: Professor Lili Liu or Professor Helong Zhang, Department of Oncology, Tangdu Hospital, The Fourth Military Medical University, 1 Xinsi Road, Xi'an, Shaanxi 710038, P.R. China E-mail: lily123fmmu@163.com

E-mail: cnxazhl@163.com

*Contributed equally

Key words: biological effects, bone morphogenetic protein 7, small-cell lung cancer, bone metastasis

\section{Introduction}

Small-cell lung cancer (SCLC) constitutes 20\% of all lung cancer cases. It is the most aggressive form and a rapidly metastasizing malignancy, with a high propensity to metastasize to bone. The metastasis is formed by disseminated tumor cells in distant organs, and is the primary cause of cancer-associated mortality in the majority of patients with cancer. Bone is one of the most common sites of metastasis for several types of tumor, including breast, prostate and lung cancer, and is accompanied by severe complications (1). Tumor metastasis is regulated by a complex molecular signaling network, which may be a major cause of poor prognosis in lung cancer. The interaction of tumor cells with the local microenvironment at the metastatic site serves a critical function in the establishment of metastases.

Bone morphogenetic proteins (BMPs) are signaling molecules that belong to the transforming growth factor $\beta$ (TGF $\beta$ ) superfamily and are pluripotent regulators of embryonic development and organogenesis, and tissue remodeling and repair $(2,3)$. As their name implies, BMPs were first identified by their ability to induce ectopic bone in vivo $(4,5)$. To date, >20 BMP family members have been identified in humans. Of these BMPs, BMP7 is a high-profile molecule owing to its pluripotent ability to regulate cellular differentiation, proliferation and apoptosis (6). As BMP-7 is a broad-spectrum growth factor, there is increasing interest in investigating its function in various malignancies, particularly bone metastasis. For example, BMP7 was identified to inhibit bone metastasis formation and growth in animal models of breast and prostate cancer $(7,8)$.

TGF $\beta$ family members, including BMPs, exhibit structural similarity and a cysteine knot (9). BMP-induced gene responses are transduced by surface serine/threonine kinase receptors and Smad family transcription factors (10). The membrane receptors contain three type I receptors [BMP receptor (BMPR)IA, BMPRIB and activin A receptor type (ACVR)I and three type II receptors (BMPRII, ACVR2A, AVCR2B) that specifically bind to BMP ligands (11). Upon binding, BMPs activate these membrane receptors, which in turn phosphorylate the cytosolic Smad proteins. Through a versatile system of Smad co-regulators, different responses of BMPs are initiated (12). In addition, BMPs also utilize Smad-independent pathways, including extracellular-signal-regulated kinase, c-Jun N-terminal kinase (JNK), and p38 mitogen-activated protein kinase pathways to transmit signals $(13,14)$. The cross-talk among these important cellular signaling pathways contributes 
to the highly intricate and multifunctional effects of BMPs in cancer. Signaling of BMPs are intracellularly regulated by the inhibitory Smads Smad6 and Smad7, extracellularly by the expression of a pseudoreceptor (BMP and activin membrane-bound inhibitor homolog) (15), and by secreted BMP antagonists, including noggin (16) and gremlin (17). Owing to the complexity of the signaling networks associated with BMPs, research into BMPs by demonstrating their stimulation may result in diverse, even contradictory, phenotypes depending on the ligand and the type of cancer investigated. The research field is currently controversial and the impact of BMP7 on SCLC as well as its downstream signaling pathway requires elucidation, which may in turn provide new insights as a therapeutic target for the clinical treatment of SCLC.

\section{Materials and methods}

Cell culture. The human SCLC cell lines SBC-3 and SBC-5 were gifts from Professor Saburo Sone and Professor Seiji Yano (Tokushima University, Tokushima, Japan). Cells were incubated at $37^{\circ} \mathrm{C}$ with $5 \% \mathrm{CO}_{2}$ in RPMI-1640 medium supplemented with $10 \%$ heated-inactivated fetal bovine serum (FBS) (both from Gibco; Thermo Fisher Scientific, Inc., Waltham, MA, USA).

Cell proliferation assay. SBC-3 and SBC-5 cells were plated in 96-well plates at a concentration of 3,000 cells/well and cultured in RPMI-1640 medium containing recombinant human (rh)BMP7 (EMD Millipore, Billerica, MA, USA) at sequential concentrations $(0,50,100,150$ and $200 \mathrm{ng} / \mathrm{ml})$. At the indicated time-points, an MTT assay was performed to determine the cell proliferation rate $(24,48$ and $72 \mathrm{~h})$. Briefly, $20 \mu 1$ MTT solution (5 mg/ml; Sigma; Merck KGaA, Darmstadt, Germany) was added to each well. After $3 \mathrm{~h}$ of incubation at $37^{\circ} \mathrm{C}$, the MTT solution was removed and $150 \mu \mathrm{l}$ DMSO was added to the wells to dissolve the blue formazan crystals. Finally, the optical density values were determined at a wavelength of $490 \mathrm{~nm}$ using a Model 680 microplate reader (Bio-Rad Laboratories, Inc., Hercules, CA, USA).

To investigate further the effect of rhBMP7 on cell proliferation, SBC-3 and SBC-5 cells were seeded into 96-well plates and incubated for 6 days (the day of plating was designated day 0). Each cell line was divided into three groups: Group A cells were incubated in RPMI-1640 medium with $150 \mathrm{ng} / \mathrm{ml} \mathrm{rhBMP} 7$ between days 1 and $6(+/+/+)$; for group B cells, rhBMP7 was supplied only on days 3 and $4(-/+/-)$; and group C cells (control) were maintained in the RPMI-1640 medium without rhBMP7 (-/-/-). MTT assays were performed every $24 \mathrm{~h}$. Each test was performed three times for accuracy.

Migration and invasion assays. Transwell inserts $(8.0 \mu \mathrm{m}$ pore size) were coated with $70 \mu$ l Matrigel (1:8 dilution) (both from Corning Incorporated, Corning, NY, USA). SBC-3 or SBC-5 cells at a density of $2 \times 10^{4}$ were resuspended in $200 \mu 1$ serum-free RPMI-1640 medium and were then transferred to the upper chamber. A $500 \mu \mathrm{l}$ volume of standard cell culture medium with or without rhBMP7 was added to the lower chamber. The cells were allowed to pass through the inserts for $24 \mathrm{~h}$ at $37^{\circ} \mathrm{C}$. The Matrigel and non-invading cells were removed using cotton swabs, whereas cells that had migrated through the Matrigel were fixed with $95 \%$ ethyl alcohol and stained with $0.5 \%$ crystal violet, and images were captured under a light microscope at x200 magnification. The mean number of migrated cells on one insert was determined in five high-magnification fields of view selected randomly. Each assay was performed three times.

For the migration assay, the inserts were not coated with Matrigel. The other processes were similar to the invasion assay. Finally, the fields of view for migrated cells were selected randomly for analysis.

Reverse transcription-quantitative polymerase chain reaction $(R T-q P C R)$. Total RNA was extracted from SBC-3 and SBC-5 cells with TRIzol ${ }^{\circledR}$ reagent (Invitrogen; Thermo Fisher Scientific, Inc.) and reverse-transcribed into cDNA using a PrimeScript RT reagent kit (Takara Bio, Inc., Otsu, Japan), according to the manufacturer's protocol. mRNA expression levels of BMPRIs were determined using qPCR in a Bio-Rad iCycler IQ ${ }^{\mathrm{TM}} 5$ instrument (Bio-Rad Laboratories, Inc.) with SYBR Master mix (Takara Bio, Inc.) and $\beta$-actin was used as a reference. The PCR procedure was as follows: Pre-denaturation at $95^{\circ} \mathrm{C}$ for $30 \mathrm{sec}$; 40 cycles of denaturation at $95^{\circ} \mathrm{C}$ for $5 \mathrm{sec}$ and annealing at $60^{\circ} \mathrm{C}$ for $30 \mathrm{sec}$. The data were analyzed using the comparative $\mathrm{Cq}\left(2^{-\Delta \Delta \mathrm{Cq}}\right)$ method (18). The primers used were as follows: BMPRIA forward, 5'-AGA TGACCAGGGAGAAACCAC-3' and reverse, 5'-CAACATTCT ATTGTCCGGCGTA-3'; BMPRIB forward, 5'-CTTTTGCGA AGTGCAGGAAAAT-3' and reverse, 5'-TGTTGACTGAGT CTTCTGGACAA-3'; ACVRI forward, 5'-GTGAAGGTCTCT CCTGCGGTA-3' and reverse, 5'-GCCATCGTTGATGCTCAG TGA-3'; $\beta$-actin forward, 5'-GATCATTGCTCCTCCTGAGC-3' and reverse, 5'-CACCTTCACCGTTCCAGTTT-3'.

Protein extraction and western blot analysis. Total protein was extracted using radioimmunoprecipitation assay buffer, and the membrane and cytosolic proteins were separated using a Membrane and Cytosol Protein Extraction kit (Beyotime Institute of Biotechnology, Haimen, China). Protein concentrations were determined using a bicinchoninic acid protein assay kit (Pierce; Thermo Fisher Scientific, Inc.). Equal amounts of protein $(30 \mu \mathrm{g})$ were separated by SDS-PAGE (10\% gels) and transferred onto polyvinylidene difluoride membranes. Following blocking with 5\% non-fat dry milk in Tris-buffered saline containing $0.05 \%$ Tween-20 for $1 \mathrm{~h}$, membranes were incubated overnight at $4^{\circ} \mathrm{C}$ with specific primary antibodies: Anti-BMPRIA and anti-BMPRIB (cat. nos. ABD51 and ABD50, respectively; 1:10,000; EMD Millipore), anti-ACVRI (cat. no. 4398; 1:1,000; Cell Signaling Technology, Inc., Danvers, MA, USA), anti-BMP7 (cat. no. ab56023; 1:500), anti-Smad2 (cat. no. ab40855; 1:1,000), anti-Smad4 (cat. no. ab40759; 1:1,000) and anti-p21 (cat. no. ab109520; 1:1,000) (all from Abcam, Cambridge, UK), and anti- $\beta$-actin (cat. no. A5441; 1:10,000; Sigma; Merck KGaA). The membranes were incubated with horseradish peroxidase (HRP)-labeled goat anti- mouse/rabbit secondary antibody (1:2,500; OriGene Technologies, Inc., Beijing, China) for $1 \mathrm{~h}$ at room temperature. Finally, the relative content of the target proteins was determined using a chemiluminescence detection system (Gel Doc XR System) and analyzed by Image Lab software (version 2.0) (both from Bio-Rad Laboratories, Inc.).

Flow cytometric analysis. Cell cycle and apoptotic analyses were performed after $48 \mathrm{~h}$ of incubation with rhBMP7 in SBC-3 
and SBC-5 cells. Briefly, to determine the cell cycle distribution, $1 \times 10^{5}$ cells were harvested and washed with PBS. Subsequently, $400 \mu \mathrm{l}$ Cell Cycle Rapid Detection Solution (Dakewe Biotech Co., Ltd., Shenzhen, China) was added and the cellular DNA content was detected by flow cytometry at an excitation wavelength of $488 \mathrm{~nm}$. The cell cycle distribution was analyzed using CellQuest (version 5.1) and ModFit software (version 3.0) (both from BD Biosciences, Franklin Lakes, NJ, USA).

Cell apoptosis was detected using an Annexin V-fluorescein isothiocyanate (FITC)-propidium iodide (PI) kit (Nanjing KeyGen Biotech Co., Ltd., Nanjing, China). Briefly, $1 \times 10^{5}$ cells were collected, washed and resuspended in $200 \mu \mathrm{l} 1 \mathrm{X}$ binding buffer. Subsequently, $10 \mu \mathrm{l}$ Annexin V-FITC and $5 \mu \mathrm{l}$ PI were added and incubated for $15 \mathrm{~min}$ at room temperature in the dark. Subsequently, $300 \mu \mathrm{l}$ binding buffer was added to each tube prior to analysis using a FACSCalibur system (BD Biosciences).

In vivo tumor formation assay. All animal studies were performed in accordance with the protocol approved by the Laboratory Animal Care of The Fourth Military Medical University (Xi'an, China). Ten female non-obese diabetic (NOD)/severe combined immunodeficient (SCID) mice (weighing between 15 and $17 \mathrm{~g}$ ) aged between 4 and 5 weeks (Huafukang Bioscience Co., Inc., Beijing, China) were used for the tumorigenic ability assay and divided into two groups (each group consisted of 5 mice). The mice were bred in a special pathogen-free grade animal facility of the Fourth Military Medical University. The mice were housed in a 12-h light/12-h dark cycle environment, with ad libitum access to food and water. SBC-3 cells and SBC-5 cells in the exponential phase were collected, washed, counted and resuspended in PBS. In total, $2 \times 10^{6}$ cells were injected into the mice via the tail vein. Mice were examined daily for general health and the progression of masses for 6 weeks. At the experimental endpoint, mice were sacrificed by anesthetization $(200 \mathrm{mg} / \mathrm{kg}$ intraperitoneal pentobarbital sodium; Sigma; Merck KGaA) and bone metastases were examined by X-ray (model MX-20; Faxitron Bioptics, LLC, Tucson, AZ, USA). Masses in the bone were collected, fixed in $10 \%$ neutral-buffered formalin, embedded in paraffin, sectioned at $4 \mu \mathrm{m}$, stained with hematoxylin and eosin (H\&E) and then visualized microscopically.

Immunohistochemistry. Paraffin-embedded sections $(4 \mu \mathrm{m})$ of tibial bone were dewaxed with xylene, rehydrated in a descending alcohol series and then immersed in $3 \% \mathrm{H}_{2} \mathrm{O}_{2}$ solution for $10 \mathrm{~min}$ to inhibit endogenous peroxidase activity. For antigen retrieval, slides were boiled in citrate buffer $(\mathrm{pH} 7.0)$ for $10 \mathrm{~min}$ in a microwave. Following blocking with $1 \%$ bovine serum albumin, the sections were incubated with polyclonal anti-BMP7 antibody (cat. no. ab27569; 1:50; Abcam) at $4^{\circ} \mathrm{C}$ overnight. Following incubation with HRP-conjugated secondary antibody for $1 \mathrm{~h}$ at room temperature, slides were developed with 3,3'-diaminobenzidine for $40 \mathrm{sec}$ and counterstained with hematoxylin for $1 \mathrm{~min}$. The primary antibody was replaced by PBS in negative controls. Two pathologists who were blinded to the clinical and histopathological outcomes evaluated the results of the staining independently.

Statistical analysis. Results are presented as the mean - standard abbreviation. For in vitro experiments, Student's t-test or one-way analysis of variance was used to determine the differences in BMP7 treatment on cell biological behaviors. $\mathrm{P}<0.05$ was considered to indicate a statistically significant difference. Statistical tests were performed using SPSS software (version 13.0.0; SPSS, Inc., Chicago, IL, USA).

\section{Results}

rhBMP7 inhibits the proliferation of SCLC cells. SBC-3 and SBC-5 cells were treated with various concentrations of rhBMP7 (0-200 ng/ml) for 24, 48 and $72 \mathrm{~h}$. As presented in Fig. 1, rhBMP7 inhibited cell proliferation in a dose- and time-dependent manner. Specifically, rhBMP7 inhibited cell proliferation at a concentration of $\geq 150 \mathrm{ng} / \mathrm{ml}$ after $24 \mathrm{~h}$ $(\mathrm{P}<0.05)$, and after $48 \mathrm{~h}, 100 \mathrm{ng} / \mathrm{ml} \mathrm{rhBMP7}$ began to exhibit a clear inhibitory effect $(\mathrm{P}<0.01)$. At $72 \mathrm{~h}$, however, the cells rapidly proliferated at all concentrations of rhBMP7. Among the three high concentrations tested (100,150 and $200 \mathrm{ng} / \mathrm{ml})$, no significant differences were observed in the inhibition of cell proliferation. On the basis of these results, a dose of $150 \mathrm{ng} / \mathrm{ml}$ was selected for further analyses.

rhBMP7 suppresses the proliferation of SCLC cells in a reversible manner in vitro. The effect of rhBMP7 on cell proliferation was investigated further. As presented in Fig. 2, it was identified that rhBMP7 treatment (+/+/+) significantly suppressed the proliferation of SBC-3 and SBC-5 cells compared with control cells (-///-), which were cultured in the absence of rhBMP7 throughout the period. Notably, withdrawal of rhBMP7 (-/+/-) rescued the cell proliferation, suggesting that rhBMP7-induced inhibition was reversible.

rhBMP7 inhibits the migratory and invasive potential of $S C L C$ cells. Next, the function of rhBMP7 in cell migration and invasion of SCLC cells was investigated using in vitro Transwell assays. The Transwell assays revealed that the number of migratory SBC-3 cells was decreased from 163-20 without rhBMP7 to 116-16 with rhBMP7, and the number of invasive SBC-3 cells was decreased from 119-15 to 73-11 (both $\mathrm{P}<0.05$; Fig. 3A). For SBC-5 cells, rhBMP7 decreased the number of migratory cells from 173-22 to 121-14, and the number of invasive cells from 167-19 to 113-13 (both $\mathrm{P}<0.05$; Fig. 3B). These results indicated that rhBMP7 was able to inhibit the migratory and invasive potential of SBC- 3 and SBC- 5 cells.

rhBMP7 induces $G_{1}$ phase arrest in SCLC cells. To investigate whether the inhibition of proliferation reflected attenuation of cell apoptosis and cell cycle, SBC-3 and SBC-5 cells treated with $150 \mathrm{ng} / \mathrm{ml} \mathrm{rhBMP} 7$ for $48 \mathrm{~h}$ were subjected to flow cytometric analysis. As presented in Fig. 4A, rhBMP7 significantly increased the apoptosis of SBC-3 cells (4.6-0.8 vs. $7.5-1.1 \%$; $\mathrm{P}<0.05)$, but did not influence the apoptosis of SBC-5 cells (9.8-2.3 vs. 10.7-2.8\%; $\mathrm{P}>0.05)$. There may be distinct mechanisms of rhBMP7 regulation of the proliferation between SBC-3 and SBC-5 cells.

With regard to the influence on cell cycle, rhBMP7 clearly decreased the proportion of cells in S phase in SBC-3 cells (from 41.86-3.4 to $30.35-2.1 \%$ ) and increased the cells in $\mathrm{G}_{1}$ phase (from 41.37-2.9 to 51.40-4.2\%). However, in SBC-5 cells, this effect was not as evident as it was in SBC-3 cells. The 

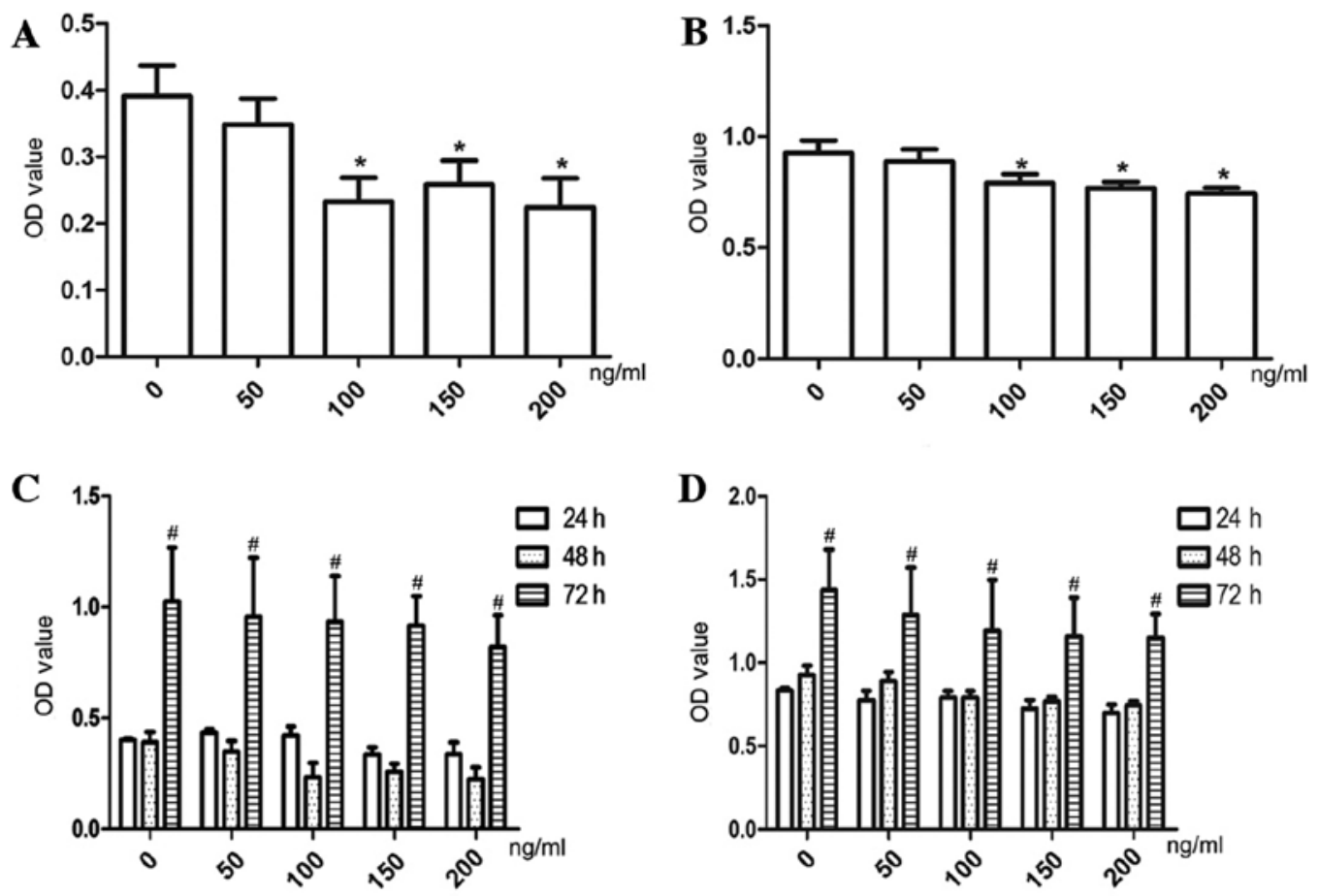

Figure 1. Effect of rhBMP7 on the proliferation of small-cell lung cancer cells. OD values of (A) SBC-3 cells and (B) SBC-5 cells incubated with rhBMP7 for $48 \mathrm{~h}$. OD values of (C) SBC-3 cells and (D) SBC-5 cells incubated with rhBMP7 for 24,48 and $72 \mathrm{~h}$. " $\mathrm{P}<0.05$ vs. control group; "P $<0.05$ vs. $24 \mathrm{~h}$ group and $48 \mathrm{~h}$ group. rhBMP7, recombinant human bone morphogenetic protein 7; OD, optical density.
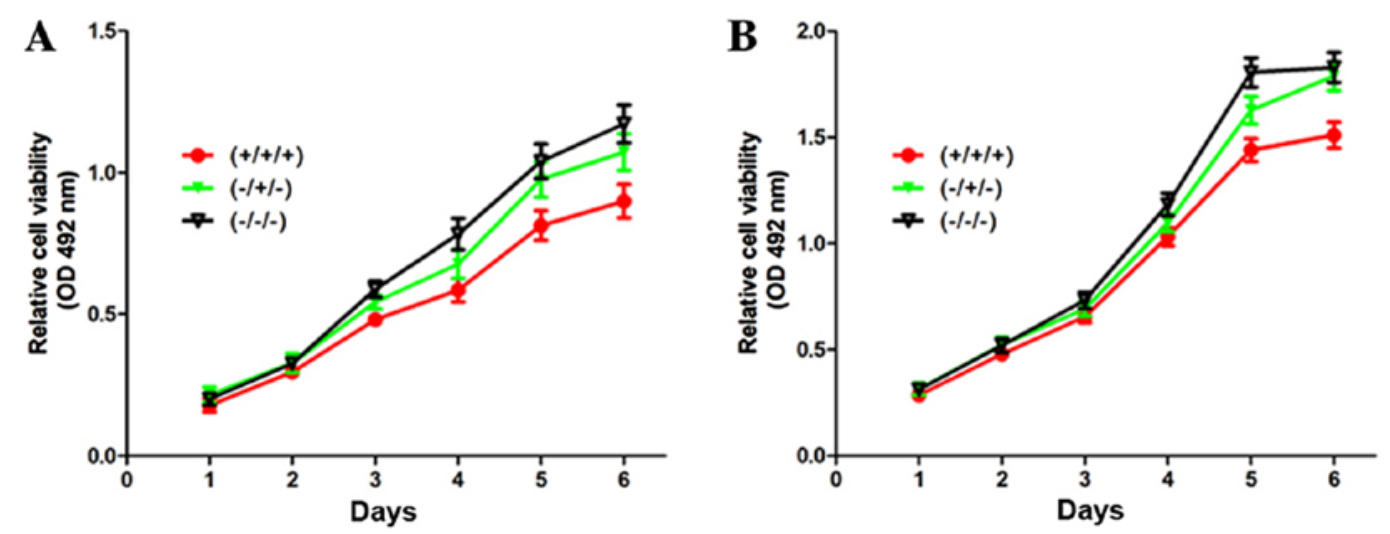

Figure 2. Effect of rhBMP7 on the proliferation of small-cell lung cancer cells. Proliferation curves in (A) SBC-3 and (B) SBC-5 cells. The (+/+/+) group was treated with rhBMP7 between days 1 and 6; the (-/+/-) group was supplied with rhBMP7 only on days 3 and 4 ; and the (-//-) group was the control in which the cells were maintained in the medium without rhBMP7. rhBMP7, recombinant human bone morphogenetic protein 7; OD, optical density.

proportion of cells in $\mathrm{S}$ phase was decreased from 49.98-4.5 to $48.83-3.7 \%$, whereas the proportion of cells in $G_{1}$ phase was increased from 42.16-3.1 to 44.18-3.6\%, suggesting that rhBMP7 induced $\mathrm{G}_{1}$ arrest in SBC-3 cells (Fig. 4B).

Expression of BMPRIs in SCLC cells. The results of the in vitro experiments suggested that rhBMP7 inhibited cell proliferation reversibly, which may serve an important function in tumorigenesis and formation of metastasis. Therefore, the expression of BMPRIs was investigated in SBC-3 and SBC-5 cells. Expression of the three type I receptor subtypes (BMPRIA, BMPRIB and ACVRI) was determined using RT-qPCR (Fig. 5A) and western blot analysis (Fig. 5B). The levels of three type I receptor subtypes (BMPRIs) were higher in SBC-5 cells compared with in SBC-3 cells at the mRNA level. With regard to proteins, there were certain notable results. In order to identify the functional receptors, membrane proteins were extracted separately. The expression levels of BMPRIA and BMPRIB in total proteins and membrane proteins were consistent with the results of qPCR. However, cytoplasmic BMPRIA and BMPRIB were higher in SBC-3 cells. Furthermore, expression of ACVRI was higher in SBC-3 cells in total and cytoplasmic proteins, although it was only weak. It was not possible to detect the expression of membrane ACVRI. It may be hypothesized that distinct expression patterns of BMPRIs in SBC-3 and SBC-5 cells determined the functions that BMP7 imposed on them.

BMP7 is significantly decreased in bone metastasis. The results of the present study supported the hypothesis that rhBMP7 
A
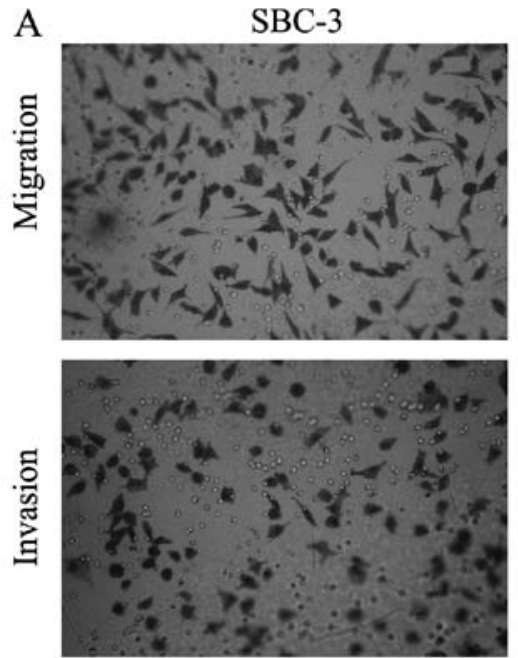

B
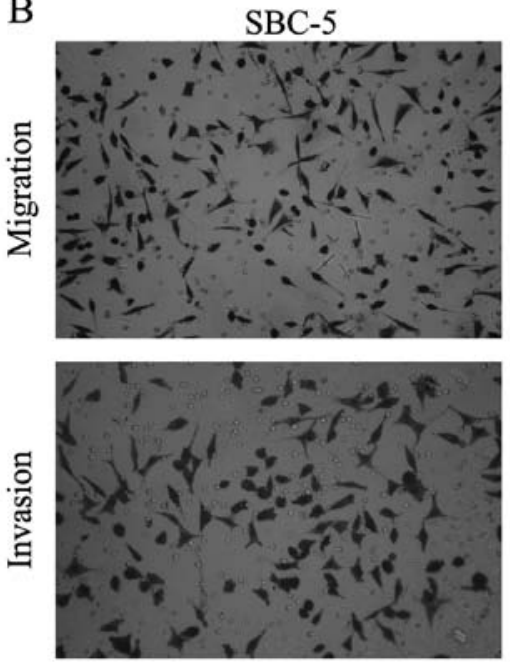

SBC-3-rhBMP7
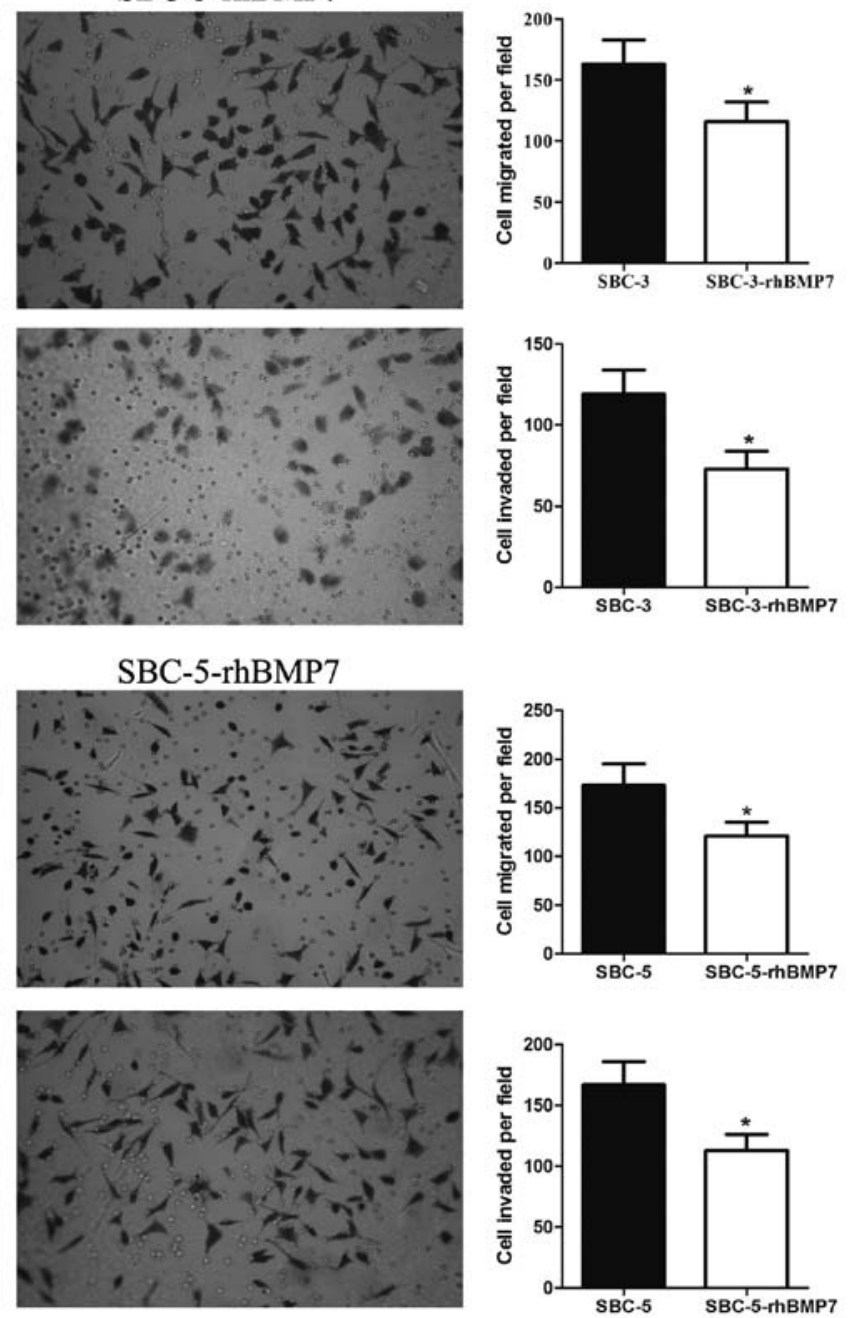

Figure 3. Effect of rhBMP7 on migration and invasion in small-cell lung cancer cells. Representative images, and quantification of the numbers, of migrated and invaded (A) SBC-3 and (B) SBC-5 cells with or without rhBMP7. rhBMP7, recombinant human bone morphogenetic protein 7. ${ }^{*}<0.05$.

served a function in tumor progression by suppressing the proliferation of SCLCs in vitro. To determine whether BMP7 was involved in bone metastasis in vivo, an animal model of bone metastasis was developed. Finally, bone metastasis was induced only in mice injected with SBC-5 cells (Fig. 6A-C). The expression of BMP7 was detected in normal bone, bone metastatic lesions of mice injected with SBC-5 cells and bone of mice injected with SBC-3 cells. The results revealed that BMP7 was markedly decreased in bone metastases (Fig. 6D-F), suggesting that BMP7 may attenuate the survival of metastatic cancer cells in bone.

BMP7 signaling pathway is adopted in SCLC cells. To investigate further the mechanism of BMP7 involved in SCLC cells, associated candidate proteins were detected by western blot analysis. SBC-3 cells generated more BMP7 compared with SBC-5 cells (Fig. 7A). Following treatment with rhBMP7 for $24 \mathrm{~h}$, the self-produced BMP7 was evidently decreased (Fig. 7A). Furthermore, Smad2 and Smad4 were decreased in SBC-3 and SBC-5 cells upon stimulation with rhBMP7, but p21 was decreased in SBC-3 cells only (Fig. 7B). These results indicated that BMP7 regulates the SCLC cell cycle through, at least in part, the Smad signaling pathway.

\section{Discussion}

BMP7 is a pleiotropic signaling protein that serves a major function during physical development. It is a member of the BMP family, and has been investigated with regard to a possible contribution to tumorigenesis. This field of research is currently controversial owing to the marked diversity in the proposed functions of various BMPs, depending on the BMP ligands and tumor types investigated.

A previous study conducted on melanoma identified that BMP7 exhibited metastatic inhibitory ability by inducing MET (19). In addition, aggressive melanoma cells escaped from BMP7-mediated autocrine proliferation inhibition via coordinated upregulation of noggin, a secretory BMP antagonist (20). Furthermore, systemic BMP7 treatment of a mouse model significantly inhibited the growth of glioma (21) and glioblastoma (22), as well as micro-metastatic deposits in the bone marrow (7), implying that BMP7 is likely to be a bone metastatic inhibitor. In the present study, it was investigated whether BMP7 inhibited proliferation in a dose- and timedependent and reversible manner, and its effect on the invasive ability of SCLC cells. Owing to an increased proliferation rate and nearly full confluence, SBC-5 cells exhibited a 

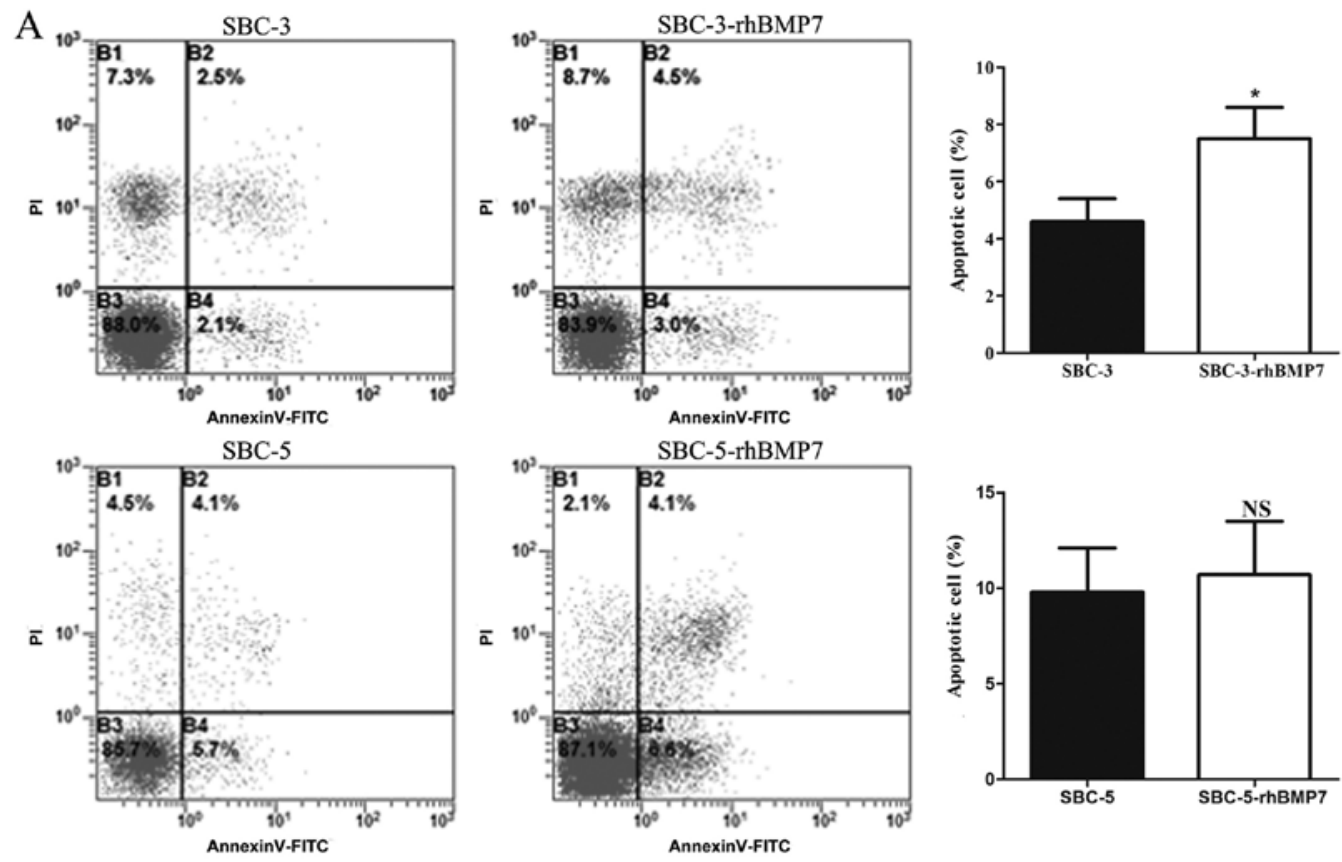

$\mathrm{B}$

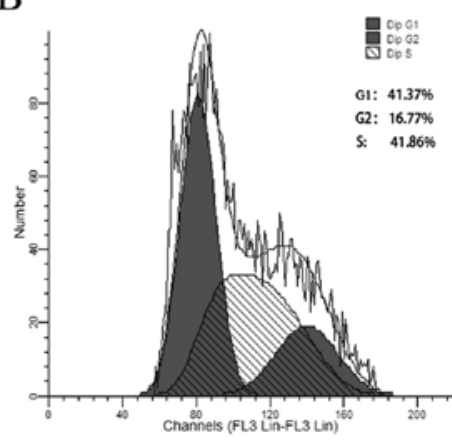

SBC-5

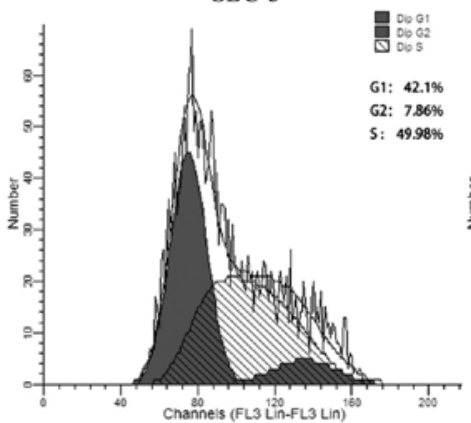

SBC-3-rhBMP7
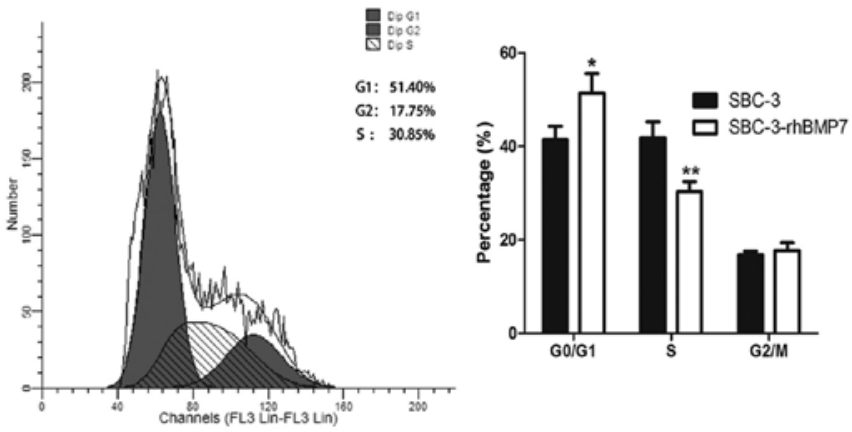
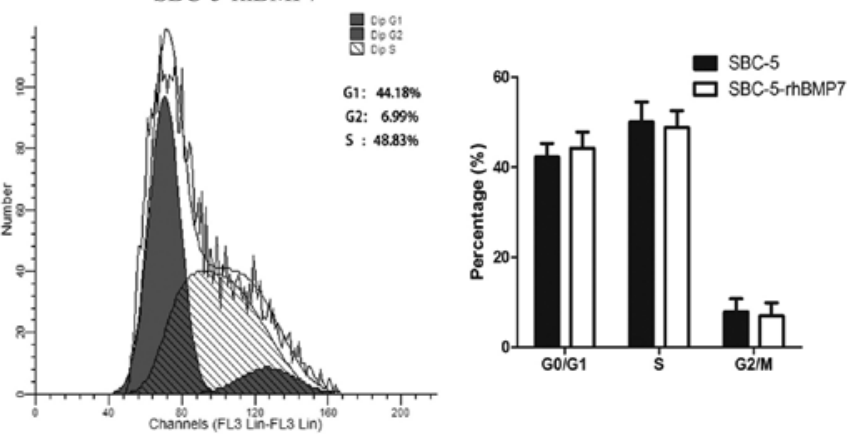

Figure 4. Effect of rhBMP7 on the cell cycle and apoptosis in small-cell lung cancer cells. (A) Apoptosis of SBC-3 and SBC-5 cell lines following exposure to rhBMP7. (B) Cell cycle analysis of SBC-3 and SBC-5 cell lines following exposure to rhBMP7. NS, not significant; ${ }^{*} \mathrm{P}<0.05,{ }^{* *} \mathrm{P}<0.01 \mathrm{vs}$. SBC-3 cells. rhBMP7, recombinant human bone morphogenetic protein 7; PI, propidium iodide; FITC, fluorescein isothiocyanate.

decrease in proliferation on day 6 in group $\mathrm{C}$, and an inhibitory effect of rhBMP7 on cell proliferation was evident. In addition, it was identified that SBC-3 cells have an enhanced secretion ability to autocrine BMP7 compared with SBC-5 cells. This may be partially inhibited by exogenous BMP7. Extracellular rhBMP7 may cause negative feedback, decreasing intrinsic BMP7 autocrine production. This may be a novel strategy to treat bone metastasis in SCLC. In the present study, SBC-3 and SBC-5 cells were selected because they share similar genetic characters, but have different potential in bone metastasis. As verified by the present in vivo study, SBC-5 cells have a propensity to metastasize to bone, whereas SBC-3 cells do not. However, BMP7 appears to exert the opposite effects in certain tumor cells. Sakai et al (23) demonstrated that augmented autocrine BMP7 signaling induced an increase in the anchorage-independent cell proliferation and metastatic potential in the bone marrow metastatic breast cancer model. In esophageal squamous cancer and colon cancer, BMP7 was identified previously to act as a promoter in invasion and metastasis $(24,25)$. Thus, functions of BMP7 are cell-specific and may be either pro-tumorigenic or anti-tumorigenic (26). 

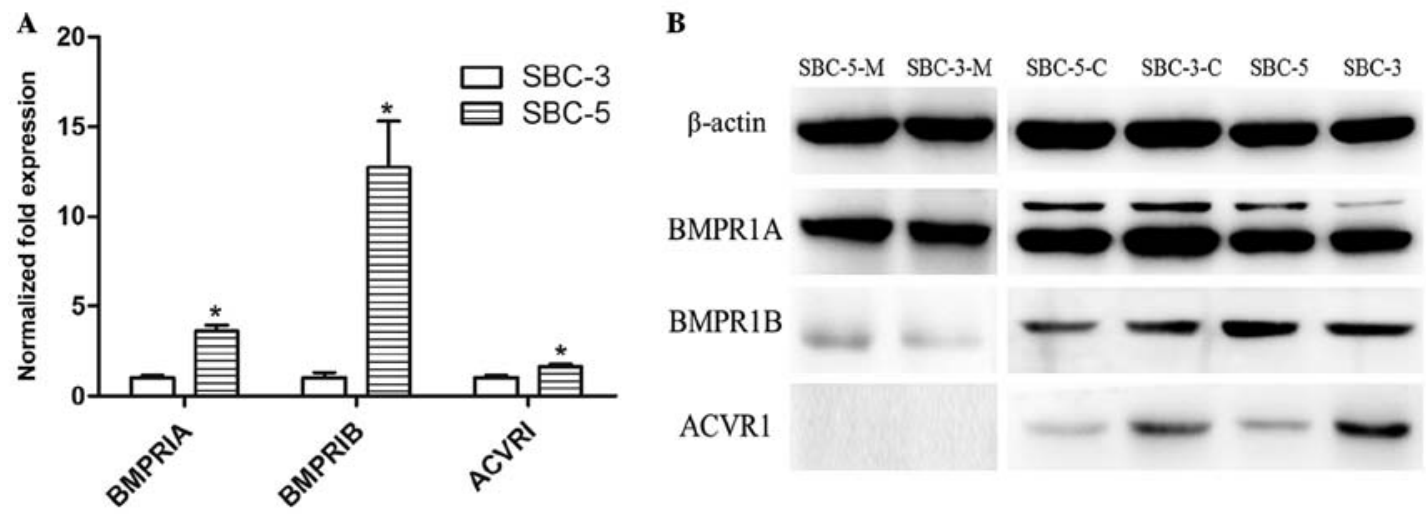

Figure 5. Expression of BMPRIs in SBC-3 and SBC-5 cells. (A) The mRNA expression level of BMPRIs in SBC-3 and SBC-5 cells. (B) The protein expression level of BMPRIs in the subset of SBC-3 and SBC-5 cells. BMPRI, type I bone morphogenetic protein receptor; ACVRI, activin A receptor type I; C, cytoplasmic protein; M, membrane protein.

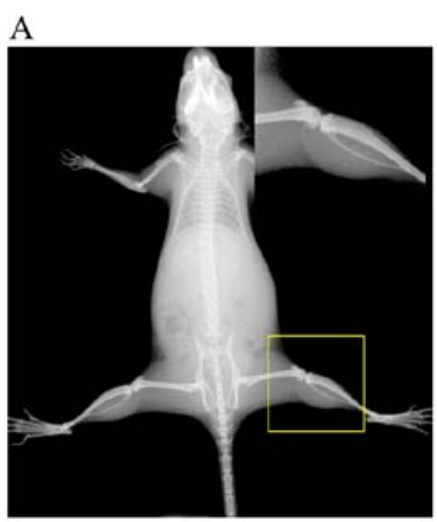

D

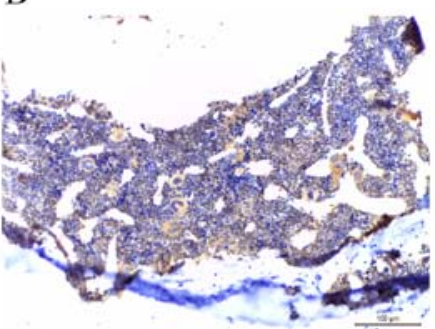

B

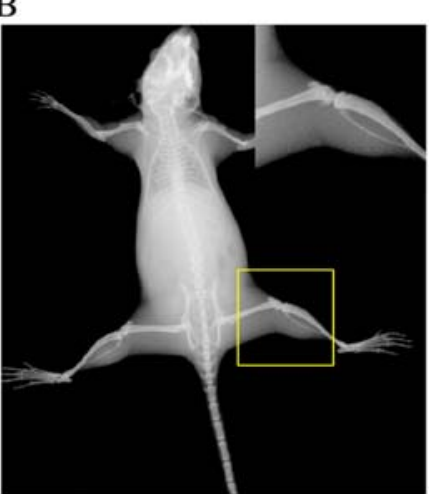

E

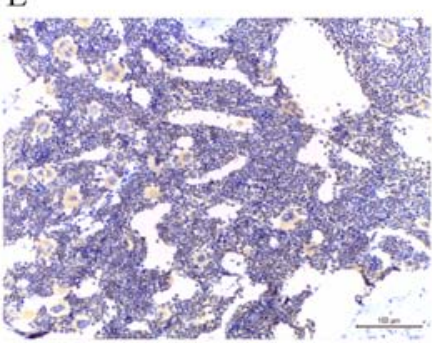

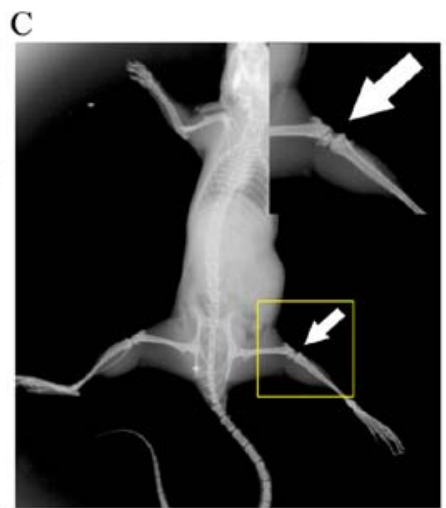

F

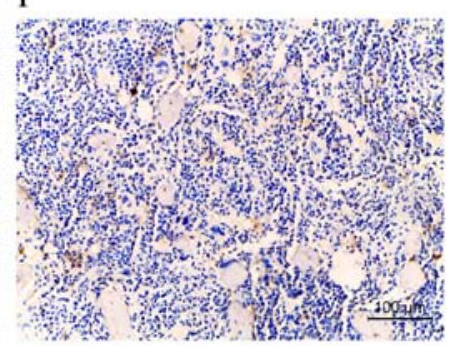

Figure 6. BMP7 expression level in bone. Representative images of (A) normal bone, (B) bone collected from mice injected with SBC-3 cells and (C) bone metastasis from mice injected with SBC-5 cells. Expression level of BMP7 in (D) normal bone, (E) bone collected from mice injected with SBC-3 cells and (F) bone metastasis from mice injected with SBC-5 cells by immunohistochemistry staining. BMP7, bone morphogenetic protein 7.

$\mathbf{A}$

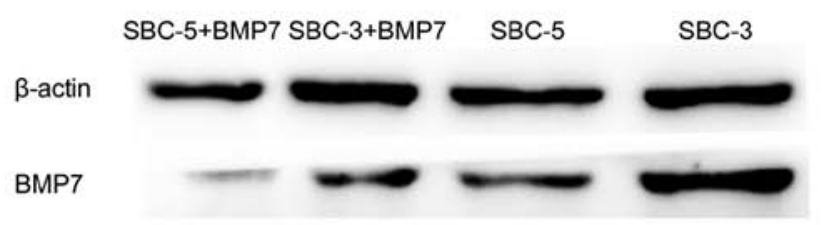

B

SBC-5+BMP7 SBC-3+BMP7

SBC-5

SBC-3

$\beta$-actin

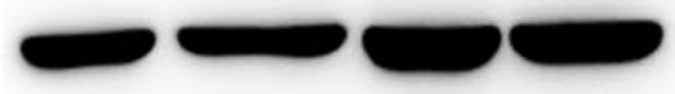

Smad-2
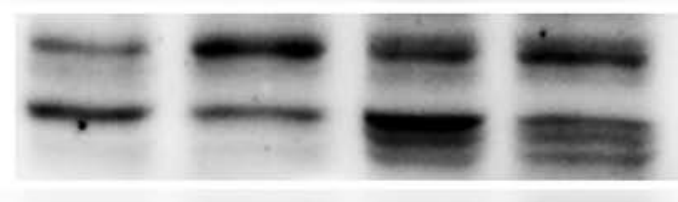

Smad-4

p21

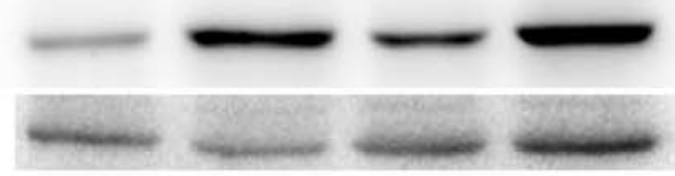

Figure 7. Expression pattern of candidate signal proteins. The expression of (A) BMP7, and (B) Smad2, Smad4 and p21 in SBC-3 and SBC-5 cells following exposure to recombinant human BMP7. BMP7, bone morphogenetic protein 7. 
In order to understand how BMP-7 exerts its anti-proliferative effects in the present study, the impact of rhBMP7 on the apoptosis and cell cycle in SBC-3 cells and SBC-5 cells was investigated. Results revealed that rhBMP7 significantly promoted the apoptosis and induced $\mathrm{G}_{1}$ arrest in SBC-3 cells, but exhibited no effect on SBC-5 cells. Thus, the mechanisms of rhBMP7 regulation of cell proliferation were distinct in SBC-3 and SBC-5 cells. In studies by Yang et al $(27,28)$, it was also proposed that the apoptotic response to BMP7 was dependent on the cell type, and, within the same cell type, was dependent on phenotype, hormone and growth factor status, and survival conditions. It was also verified whether BMP7 inhibited the prostate cancer cell proliferation through stabilizing the levels of survivin and restoring the functions of JNK, which contributed to the anti-apoptotic activity of BMP7 $(27,28)$. BMP7 exerted its function by binding to BMPRI. Three type I receptors were reported. BMPRIB served a negative function for inducing proliferation and aggressiveness in breast cancer cells by BMP, but BMPRIA appeared to serve a regulatory function (29). In SBC-3 cells and SBC-5 cells, different patterns of BMPRI expression meant that BMP7 adopted different downstream signaling pathways. Total and membrane BMPR-IA and BMPR-IB were expressed at higher levels in SBC-5 cells, whereas cytoplasmic BMPR-IA and BMPR-IB were higher in SBC-3 cells. However, AVCRI was highly expressed in SBC-3 cells, suggesting that BMP7 inhibited SBC-3 aggressiveness and tumorigenesis mainly by activating AVCRI. Although the expression of AVCRI was low, it may serve a critical function. There was a contradictory result about the expression of AVCRI, which was higher in SBC-5 cells at the mRNA level, but higher in SBC-3 cells at the protein level. As is well-known, protein is the final actor of any biomolecule. Thus, AVCRI was highly expressed in SBC-3 cells compared with in SBC-5 cells. Upon binding to BMPRIs, BMP7 pass down the signal via the Smad pathway or non-Smad pathway. Smad2 and Smad4 were downregulated following stimulation with BMP7 in SCLC cells. The alterations in the sub-bands of Smad2 were notable, with certain sub-bands enhanced, whereas others were weakened. This may be due to the alterations in the subtypes of Smad2, which requires further validation. In addition, as an important cell cycle regulator, p21 levels were also decreased in SBC-3 cells, but there was no change in p21 levels in SBC-5 cells. Thus, the signaling pathway associated with BMP7 is complicated. Extrinsic rhBMP7 exerted different biological effects on SBC-3 and SBC-5 cells. As a secretory protein, BMP7 employs different receptors to trigger downstream signaling pathways. A high dose of rhBMP7 was also linked to cell cycle arrest and apoptotic activation. In addition, the BMP antagonists noggin and follostatin are also the determining factors for the cellular response to BMP7. Interestingly, the expression of these antagonists may be regulated by BMP7 itself probably via an autocrine or paracrine feedback loop (30). In addition, microRNA (31), gremlin (32) and angiopoietin-like 4 (33) also regulated the expression of BMP7 as an upstream regulator. However, further research to understand the complexity of BMP7 signaling in SCLC is required.

Clinical data revealed that BMP7 was associated with the clinicopathological features. For example, in esophageal squamous cell carcinoma, the expression of BMP7 indicated a poorer prognosis. This was because the BMP7-positive group demonstrated deeper progression, more advanced stages and greater venous invasion compared with the BMP7negative group (34). Furthermore, in gastric cancer, BMP7 is an independent prognostic factor, and was associated with tumor size, nodal involvement, lymphatic invasion, venous invasion and histology, as well as the patient's postoperative outcome (35). Suppression of endogenous BMP7 expression by short interfering RNA in highly metastatic cell lines led to the upregulation of epithelial cadherin and downregulation of MMP-9, resulting in the attenuation of cell migration and invasion in in vitro and in vivo studies (36). However, BMP7 is a double-edged sword. In clinical prostate cancer specimens and human cancer cell lines, tumorigenicity and invasive behavior were associated with decreased expression of BMP7 (8). BMP7 expression was accompanied with improved surgical outcomes in renal cell carcinoma (37). In the present study, the bone metastasis model in NOD/SCID mice was established and the expression of BMP7 was compared in normal bone and metastatic bone. It was confirmed that BMP7 was downregulated in the bone lesions. However, further research is required to elucidate whether BMP7 is able to inhibit the progression of bone metastasis in SCLC.

In summary, the results of the present study suggested that BMP7 served a major function in SCLC progression. BMP7 is able to inhibit proliferation, migration, and invasion of SCLC cells. Of note, its inhibitory effect on cell proliferation was reversible. BMP7 may exert these functions by inducing apoptosis and/or $\mathrm{G}_{1}$ arrest in the cell cycle. Furthermore, SBC-3 cells demonstrated a stronger property of secreting BMP7 and the BMPRI pattern expressed in SBC-3 cells and SBC-5 cells was distinct, which may be the underlying reasons for the different responses of SCLC cells to BMP7 exposure. Further investigation of the mechanisms by which BMP7 expression and signaling are modulated in tumor cells is required and should provide novel and deeper insights into the mechanisms underlying SCLC metastasis as well as strategies for its effective prevention.

\section{Acknowledgements}

The authors are grateful for the interpretation of immunoassay results provided by the Professor Wei Zhang and Dr Yuan Ge (Department of Pathology, Tangdu Hospital, Xi'an, China). The authors thank them for their helpful discussions.

\section{Funding}

The present study was supported by National Natural Science Foundation of China (grant no. 81572251).

\section{Availability of data and materials}

All data generated or analyzed during this study are included in this published article.

\section{Authors' contributions}

WS and HZ designed the study. WS and HP performed all the in vitro experiments. WS and BX performed the animal study. 
WS, HP and LD analyzed the data. LL provided guidance during the study. All authors contributed to the writing of the manuscript. All authors have read and approved the final manuscript.

\section{Ethics approval and consent to participate}

All animal studies were performed in accordance with the protocol approved by the Laboratory Animal Care of the Fourth Military Medical University (Xi'an, China).

\section{Patient consent for publication}

Not applicable.

\section{Competing interests}

The authors declare that they have no competing interests.

\section{References}

1. Jemal A, Siegel R, Ward E, Hao Y, Xu J and Thun MJ: Cancer statistics, 2009. CA Cancer J Clin 59: 225-249, 2009.

2. Graff JM: Embryonic patterning: To BMP or not to BMP, that is the question. Cell 89: 171-174, 1997.

3. Wozney JM and Rosen V: Bone morphogenetic protein and bone morphogenetic protein gene family in bone formation and repair. Clin Orthop Relat Res 346: 26-37, 1998.

4. Urist MR: Bone: Formation by autoinduction. Science 150: 893-899, 1965

5. Wozney JM, Rosen V, Celeste AJ, Mitsock LM, Whitters MJ, Kriz RW, Hewick RM and Wang EA: Novel regulators of bone formation: Molecular clones and activities. Science 242 1528-1534, 1988

6. Boon MR, van der Horst G, van der Pluijm G, Tamsma JT, Smit JW and Rensen PC: Bone morphogenetic protein 7: A broad-spectrum growth factor with multiple target therapeutic potency. Cytokine Growth Factor Rev 22: 221-229, 2011.

7. Buijs JT, Henriquez NV, van Overveld PG, van der Horst G, Que I, Schwaninger R, Rentsch C, Ten Dijke P, Cleton-Jansen AM, Driouch K, et al: Bone morphogenetic protein 7 in the development and treatment of bone metastases from breast cancer. Cancer Res 67 $8742-8751,2007$.

8. Buijs JT, Rentsch CA, van der Horst G, van Overveld PG, Wetterwald A, Schwaninger R, Henriquez NV, Ten Dijke P, Borovecki F, Markwalder R, et al: BMP7, a putative regulator of epithelial homeostasis in the human prostate, is a potent inhibitor of prostate cancer bone metastasis in vivo. Am J Pathol 171: 1047-1057, 2007

9. Botchkarev VA: Bone morphogenetic proteins and their antagonists in skin and hair follicle biology. J Invest Dermatol 120: 36-47, 2003.

10. Miyazono K, Maeda S and Imamura T: BMP receptor signaling: Transcriptional targets, regulation of signals, and signaling cross-talk. Cytokine Growth Factor Rev 16: 251-263, 2005.

11. Kawabata M, Imamura T and Miyazono K: Signal transduction by bone morphogenetic proteins. Cytokine Growth Factor Rev 9: 49-61, 1998.

12. Massagué J, Seoane J and Wotton D: Smad transcription factors. Genes Dev 19: 2783-2810, 2005.

13. Derynck R and Zhang YE: Smad-dependent and Smadindependent pathways in TGF-beta family signalling. Nature 425: 577-584, 2003.

14. ten Dijke P, Korchynskyi O, Valdimarsdottir G and Goumans MJ: Controlling cell fate by bone morphogenetic protein receptors. Mol Cell Endocrinol 211: 105-113, 2003.

15. Onichtchouk D, Chen YG, Dosch R, Gawantka V, Delius H, Massagué $\mathrm{J}$ and Niehrs C: Silencing of TGF-beta signalling by the pseudoreceptor BAMBI. Nature 401: 480-485, 1999.

16. Groppe J, Greenwald J, Wiater E, Rodriguez-Leon J, Economides AN, Kwiatkowski W, Affolter M, Vale WW, Izpisua Belmonte JC and Choe S: Structural basis of BMP signalling inhibition by the cystine knot protein Noggin. Nature 420: 636-642, 2002.
17. Hsu DR, Economides AN, Wang X, Eimon PM and Harland RM: The Xenopus dorsalizing factor Gremlin identifies a novel family of secreted proteins that antagonize BMP activities. Mol Cell 1: 673-683, 1998.

18. Livak KJ and Schmittgen TD: Analysis of relative gene expression data using real-time quantitative PCR and the 2(-Delta Delta C(T)) method. Methods 25: 402-408, 2001.

19. Na YR, Seok SH, Kim DJ, Han JH, Kim TH, Jung H, Lee BH and Park JH: Bone morphogenetic protein 7 induces mesenchymalto-epithelial transition in melanoma cells, leading to inhibition of metastasis. Cancer Sci 100: 2218-2225, 2009.

20. Hsu MY, Rovinsky SA, Lai CY, Qasem S, Liu X, How J, Engelhardt JF and Murphy GF: Aggressive melanoma cells escape from BMP7-mediated autocrine growth inhibition through coordinated Noggin upregulation. Lab Invest 88: 842-855, 2008.

21. Klose A, Waerzeggers Y, Monfared P, Vukicevic S, Kaijzel EL, Winkeler A, Wickenhauser C, Löwik CW and Jacobs AH: Imaging bone morphogenetic protein 7 induced cell cycle arrest in experimental gliomas. Neoplasia 13: 276-285, 2011.

22. González-Gómez P, Crecente-Campo J, Zahonero $\mathrm{C}$, de la Fuente M, Hernández-Laín A, Mira H, Sánchez-Gómez $\mathrm{P}$ and Garcia-Fuentes M: Controlled release microspheres loaded with BMP7 suppress primary tumors from human glioblastoma. Oncotarget 6: 10950-10963, 2015.

23. Sakai H, Furihata M, Matsuda C, Takahashi M, Miyazaki H, Konakahara T, Imamura T and Okada T: Augmented autocrine bone morphogenic protein (BMP) 7 signaling increases the metastatic potential of mouse breast cancer cells. Clin Exp Metastasis 29: 327-338, 2012.

24. Hu M, Cui F, Liu F, Wang J, Wei X and Li Y: BMP signaling pathways affect differently migration and invasion of esophageal squamous cancer cells. Int J Oncol 50: 193-202, 2017.

25. Zhang T, Fu J, Li Y, Wang Y, Zhang L and Liu Y: Bone morphogenetic protein 7 is associated with the nodal invasion of colon cancer. Oncol Lett 11: 1707-1712, 2016.

26. Tu WH, Thomas TZ, Masumori N, Bhowmick NA, Gorska AE, Shyr Y, Kasper S, Case T, Roberts RL, Shappell SB, et al: The loss of TGF-beta signaling promotes prostate cancer metastasis. Neoplasia 5: 267-277, 2003

27. Yang S,Zhong C,Frenkel B, Reddi AH and Roy-Burman P: Diverse biological effect and Smad signaling of bone morphogenetic protein 7 in prostate tumor cells. Cancer Res 65: 5769-5777, 2005.

28. Yang S, Lim M, Pham LK, Kendall SE, Reddi AH, Altieri DC and Roy-Burman P: Bone morphogenetic protein 7 protects prostate cancer cells from stress-induced apoptosis via both Smad and c-Jun NH2-terminal kinase pathways. Cancer Res 66: 4285-4290, 2006.

29. Bokobza SM, Ye L, Kynaston HE, Mansel RE and Jiang WG: Reduced expression of BMPR-IB correlates with poor prognosis and increased proliferation of breast cancer cells. Cancer Genomics Proteomics 6: 101-108, 2009.

30. Ye L, Lewis-Russell JM, Kynaston H and Jiang WG: Endogenous bone morphogenetic protein-7 controls the motility of prostate cancer cells through regulation of bone morphogenetic protein antagonists. J Urol 178: 1086-1091, 2007.

31. Ying X, Sun Y and He P: MicroRNA-137 inhibits BMP7 to enhance the epithelial-mesenchymal transition of breast cancer cells. Oncotarget 8: 18348-18358, 2017.

32. Yin Y, Yang Y, Yang L, Yang Y, Li C, Liu X and Qu Y: Overexpression of Gremlin promotes non-small cell lung cancer progression. Tumour Biol 37: 2597-2602, 2016

33. Li X, Chen T, Shi Q, Li J, Cai S, Zhou P, Zhong Y and Yao L: Angiopoietin-like 4 enhances metastasis and inhibits apoptosis via inducing bone morphogenetic protein 7 in colorectal cancer cells. Biochem Biophys Res Commun 467: 128-134, 2015.

34. Megumi K, Ishigami S, Uchikado Y, Kita Y, Okumura H, Matsumoto M,Uenosono Y,Arigami T, Kijima Y,Kitazono M, et al: Clinicopathological significance of BMP7 expression in esophageal squamous cell carcinoma. Ann Surg Oncol 19: 2066-2071, 2012.

35. Aoki M, Ishigami S, Uenosono Y, Arigami T, Uchikado Y, Kita Y, Kurahara H, Matsumoto M, Ueno S and Natsugoe S: Expression of BMP-7 in human gastric cancer and its clinical significance. Br J Cancer 104: 714-718, 2011.

36. Xu G, Tang S, Yang J, Chen K, Kang J, Zhao G, Feng F, Yang X, Zhao L, Lu Q, et al: BMP7 expression in esophageal squamous cell carcinoma and its potential role in modulating metastasis. Dig Dis Sci 58: 1871-1879, 2013.

37. Kwak C, Park YH, Kim IY, Moon KC and Ku JH: Expression of bone morphogenetic proteins, the subfamily of the transforming growth factor-beta superfamily, in renal cell carcinoma. J Urol 178: 1062-1067, 2007. 